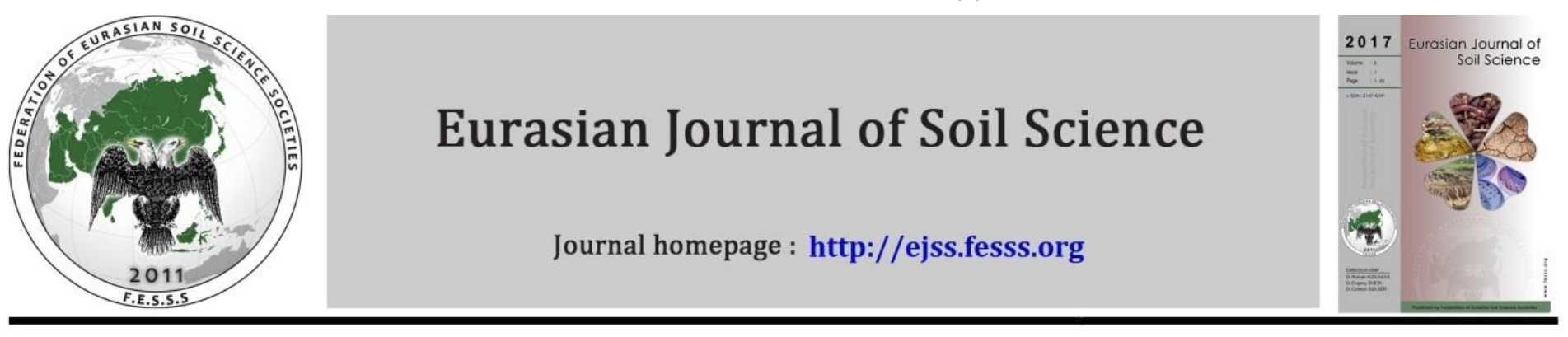

\title{
Polluted soil leaching: unsaturated conditions and flow rate effects
}

\section{Chourouk Mathlouthi, Mariem Kacem *, Zyed Mesticou, Philippe Dubujet}

Université de Lyon, Laboratoire de Tribologie et de Dynamique des Systèmes «LTDS», Ecole nationale d’Ingénieurs de Saint Etienne, France

\section{Article Info}

Received : 12.09 .2016

Accepted : 12.12.2016

\begin{abstract}
In this study, soil samples are extracted from a polluted site at different depths. Soils texture and pollutant presence are different with depth. Preliminary analyzes showed pollution by heavy metals. To simulate soil leaching operation in static condition, a series of leaching tests are conducted in laboratory column under conditions of upflow unsaturated soil. Electrical conductivity and $\mathrm{pH}$ measurements on the recovered leachate are performed. Different flow rates are tested. Comparison of different profiles shows that the dissolved pollutants are concentrated in the upper soil levels and disperse weakly in the lower parts which confirm the nature of anthropogenic pollution of heavy metals. Water mobilizes a high amount of dissolved ionic substances up to $80 \%$ of the initial concentration. The increase in flow rate requires more pore volume injected to achieve the maximum clearance rate. The down flow condition extracts a small amount of dissolved substances.
\end{abstract}

Keywords: Soil column, soil leaching, unsaturated soil, flow rate effect.

(C) 2017 Federation of Eurasian Soil Science Societies. All rights reserved

\section{Introduction}

Leaching by rainwater is the phenomenon frequently found in nature. It allows the passage of various fine and soluble materials through the different soil layers. Different ions from soluble material in water are mobilized. These substances may be salts, various inorganic or organic. This method is also used as a method of depollution of certain types of soils. The leachate can be water associated with appropriate reagents enabling a more efficient separation of the extracted products. The reactants are used in the case of organic or metallic contamination. These pollutants having a low solubility in pure water, several studies have developed various reactants to improve the leaching performance such as acids, sodium hydroxide, cations, complexing agents or oxidation/reduction agents, (Mulligan et al., 2001 ; Dermont et al., 2008; Viglianti et al., 2008 ; Yang et al., 2012 ; Fedje et al., 2013). For the most pollutants the use of an active agent improves the extraction efficiency to 100 times (AAEE, 1993).

Leachability depends on some physical parameters (homogeneity, particle size, porosity, permeability of the solid phase influencing the flow rate and contact time between solution and solid, and temperature). Other parameters such as $\mathrm{pH}$ value, redox conditions, total organic carbon content, chemical reaction kinetics, chemical speciation of contaminants, and complexation with other constituents could affect leachability performances.

\footnotetext{
* Corresponding author.

Université de Lyon, Laboratoire de Tribologie et de Dynamique des Systèmes «LTDS», Ecole nationale d'Ingénieurs de Saint Etienne, France

Tel.: +477437537 
Several studies have focused on the interactions between heavy metals "HM" and water. These works are developed largely in the context of soil remediation studies by chemical washing. Most studies have focused on identifying the important parameters which influence the mobilization of $\mathrm{HM}$, by changing the chemical conditions of the environment by the use of different mineralogy of soil (Matos et al., 2001; Kumar et al., 2013) or different acidities of the washing solution (Lo et al., 2011; Jean-soro et al., 2012 ; Fedje et al., 2013) or different salinities (Chappell et al., 2013 ; Li et al., 2011). Kumar et al. (2013) made a soil column leaching using a mixture of deionized water and highway road dust to mimic condition of urban runoff received by artificial infiltration facilities. The competition retention and mobility in the presence of different HM have been the subject of study of Lafuente et al. (2008).

Some works have studied the mobility of some organic and mineral compounds by comparison of results from different experimental methods as column, batch, sequential extraction and in-situ experiment (Plassard et al., 2000; Kalbe et al., 2008; Beesley et al., 2010 ; Wennrich et al., 2012, Colombani et al., 2015). A batch test may not be representative of natural conditions. In particular for batch tests, equilibrium conditions are assumed to have been reached, the $\mathrm{pH}$ value does not represent the $\mathrm{pH}$ of the on-site leaching environment. The continued leaching of contaminants into the environment is not addressed. Column studies seem to reflect leaching conditions more realistic.

Few studies have examined the influence of flow rate on the mobility of HM (Pang et al., 2002; Wehrer and Totche 2008; Lo et al., 2011). In these works, the washing liquid which is a mixing of water and a reagent is operated in saturated columns. Wehrer and Totsche (2008) have performed experiments at different flow rates for two different sorts of soils. They highlighted that the mobility of pollutants is influenced by the imposed rates. Their experiments are conducted in an environment full of organic and inorganic pollutants. Lo et al. (2011) found different results depending on the metal to be extracted. For the same performance some metals are extracted with a low flow rate using less pore volume than with a high flow rate. Other kind of heavy metals requires less pore volumes with high flow rates to achieve the same performance as using a low flow.

The purpose of this work is to identify the impact of flow on leaching and therefore the mobility of dissolved and desorbed ionic mineral substances in unsaturated soil conditions. The experimental results on leaching column tests of three soils extracted from three depths are first analyzed. Different rates are applied to assess its impact on leaching protocol.

\section{Material and Methods}

\section{Soils characterization}

Soil samples are extracted from an old service station site located south west of Lyon, at an altitude of about $182 \mathrm{~m}$ from the surface of the sea. According to the Geological Map No. 698 Lyon (France) edited by the BRGM (BRGM, 1978). The site is located to the right of wurmiennes fluvial sediments, called "terrace of Villeurbanne." Taking into account lithological sections of the site and observations on land, the nature of soil is sandy.

Three soil models are extracted from the site at different depths (Figure 1):

- Soil 1 : at depth of $1.5 \mathrm{~m}$;

- Soil 2 : at depth of $2.3 \mathrm{~m}$;

- Soil 3 : at depth of de $3.5 \mathrm{~m}$.

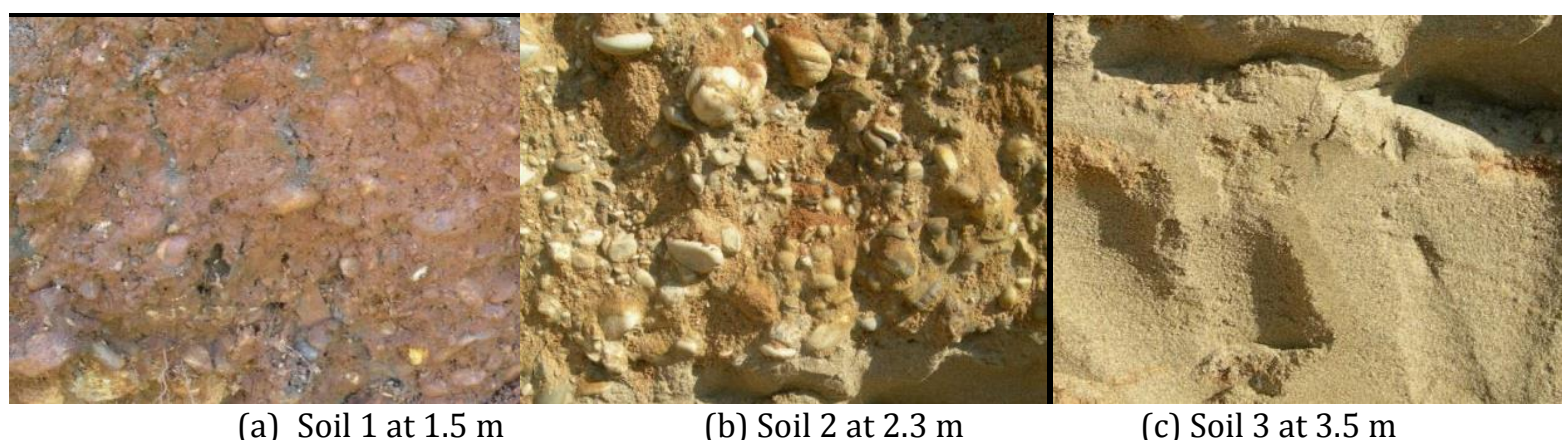

(a) Soil 1 at $1.5 \mathrm{~m}$

(b) Soil 2 at $2.3 \mathrm{~m}$

(c) Soil 3 at $3.5 \mathrm{~m}$

Figure 1. Photos of soil samples 
All samples are prepared by air-dried at $30^{\circ} \mathrm{C}$ during $48 \mathrm{~h}$ and sieved between $50 \mu \mathrm{m}$ and $10 \mathrm{~mm}$. The clay and silt fractions are then removed. Particle size distribution curves are determined in agreement to French norm P 94-056. The densities are determined by pycnometers according to French standard P 94-054. The contents of water samples are determined by drying in an oven according to the French standard P 94-050. The measurement of soil permeability was carried out under the procedure, called a "constant loads." The soils 1 and 2 have comparable properties. They exhibit a high Uniformity coefficient " $\mathrm{Cu}$ " indicating graded size distribution. They contain 20 to $25 \%$ of fine sand out of a $40 \%$ of sand total. The other $60 \%$ have a particle size between $2 \mathrm{~mm}$ and $10 \mathrm{~mm}$. The soil 3 is a sandy soil homogeneous and uniform $(C u=2.62)$, with a higher water content than the other two soils. The curvature factor shows that the three soils are not well graded. Table 1 summarizes the main properties of used soils.

Table 1. Soils properties

\begin{tabular}{lccc}
\hline & Soil 1 & Soil 2 & Soil 3 \\
\hline Buk density $\left(\mathrm{Kg}^{-3} \mathrm{~m}^{-3}\right.$ & 2600 & 2500 & 2778 \\
Water content $(\%)$ & 1.51 & 1.5 & 5.03 \\
Permeability $K_{s}\left(\mathrm{~m}^{-1} \mathrm{~s}^{-}\right)$ & $7.9510^{-4}$ & $7.9210-4$ & $0.1710^{-4}$ \\
Particle size distribution & & 4.6 & 0.14 \\
D50 (mm) & 4.4 & 72.22 & 2.62 \\
Uniformity coefficient Cu & 76.47 & 0.26 & 0.87 \\
Coefficient of curvature Cc & 0.42 & & \\
\hline
\end{tabular}

\section{Pollution analysis}

Chemical analyzes are made by the Alcontrol laboratory (France) on samples of the same study site. The found pollutants in this site can be classified into three families:

- Heavy metals ;

- Polycyclic aliphatic hydrocarbons PAH, light hydrocarbons (C5-C10), heavy hydrocarbons (C10-C40) ;

- BTEX (Benzene, Toluene, Xylene and Methyl-benzene).

Table 2 summarizes the concentrations of the various found pollutants for a mixture of equal masses of 3 samples at different depths and the concentration limits in order to classify a soil as contaminated (BRGM, 2008). The considered reference values are determined from the total contents of trace elements in soils in France to rank the value ranges in "ordinary" values and natural anomalies (BRGM, 2008). These results show pollution from copper, mercury and lead. Arsenic, cadmium and zinc concentrations exist with the limit of the maximum permissible concentrations.

Table 2. Soil concentrations in HM, hydrocarbons, BETEX and PAH

\begin{tabular}{|c|c|c|}
\hline Pollutant & Concentration (mg.kg-1) & Values observed on « ordinary » soils $\left(\mathrm{mg}^{\mathrm{k}} \mathrm{kg}^{-1}\right)(\mathrm{BRGM}, 2008)$ \\
\hline \multicolumn{3}{|r|}{ Heavy metals } \\
\hline Arsenic (As) & 22 & 1 to 25 \\
\hline Cadmium (Cd) & 0.5 & 0.05 to 0.45 \\
\hline Chromium (Cr) & 18 & 10 to 90 \\
\hline Copper $(\mathrm{Cu})$ & 46 & 2 to 20 \\
\hline Mercury (Mg) & 1 & 0.02 to 0.1 \\
\hline Nickel (Ni) & 14 & 2 to 60 \\
\hline Lead $(\mathrm{Pb})$ & 120 & 9 to 50 \\
\hline Zinc $(\mathrm{Zn})$ & 99 & 10 to 100 \\
\hline \multicolumn{3}{|c|}{ Hydrocarbons } \\
\hline $\begin{array}{l}\text { Hydrocarbon index } \\
\text { (HCT) C10-C40 }\end{array}$ & 24,8 & 75 \\
\hline $\begin{array}{l}\text { Hydrocarbon index C5- } \\
\text { C10 }\end{array}$ & $<10$ & 5 \\
\hline \multicolumn{3}{|r|}{ BTEX } \\
\hline All the BETEX & $<0.1$ & 0.1 \\
\hline \multicolumn{3}{|r|}{$\mathrm{PAH}$} \\
\hline Total of $16 \mathrm{PAH}$ & 0.136 & 24 \\
\hline
\end{tabular}

\section{Experimental device}

The soil sample is placed in a Plexiglas column of $20 \mathrm{~cm}$ height and $7 \mathrm{~cm}$ inside diameter. It disposes of orifice of $0.9 \mathrm{~cm}$ at the outlet. The column is placed in vertical position. The sample is placed in layers and 
compacted manually using a cylindrical mass. The solution used here is deionized water with a conductivity of $81 \mu \mathrm{S} / \mathrm{cm}$ and a $\mathrm{pH}$ of about 6.3. A conductimeter is used to measure the electrical conductivity of the leachate. That measure allows quantifying the ionic compound restitution rate downstream of the soil sample.

First experiments called "Up flow tests" allow having information on leaching of a polluted soil near to the saturation. This can be the case of high rainfall approaching the soil from saturated condition. Tests are conducted with the flow direction from bottom to top of the column. The porous bed has $19 \mathrm{~cm}$ height. At the inlet and outlet of the column, a textile filter is disposed to prevent the migration of the soil grains due to the flow. The column is saturated with $\mathrm{CO}_{2}$ to avoid air bubbles. A constant rate flow was applied using a peristaltic pump at the inlet of the column to maintain the saturation of soil sample. The output pressure is equal to the atmospheric pressure. The experiment is then composed of transient column saturation phase equal approximately to one porous volume and a saturated phase.

Various flow values are applied during these tests: 4.7; 10; 20; 40 and $60 \mathrm{ml}^{\mathrm{min}}{ }^{-1}$. These values are within the validity range of Darcy's law. A pH meter is used to measure the $\mathrm{pH}$ of the leachate. Table 3 summarizes the experimental conditions of the different column tests. During rain events, the most realistic situation corresponds to a downward leaching. Second experiments called "Down flow tests" are conducted with the flow direction from top to bottom of the column. At the entrance of the column, bed of glass beads of $2 \mathrm{~mm}$ in diameter are placed in a thickness of $2 \mathrm{~cm}$ to obtain a homogeneous distribution of the water flow. The porous bed has $17 \mathrm{~cm}$ height.

The experiment consists in passing a quantity of 1 liter of water corresponding approximatively to 5 pore volumes. The output condition is the atmospheric pressure. Two flows are used: $4.7 \mathrm{ml} \mathrm{min}^{-1}$ and 113.6 $\mathrm{ml} \mathrm{min}^{-1}$. Once the injected amount of water is complete, the pump is stopped. The leachate is recovered over time and analyzed. The output flow is then variable.

\section{Results and Discussion}

\section{Up flow tests}

The $\mathrm{pH}$ and conductivity are measured in the case of 3 soils at flow of $4.7 \mathrm{ml}^{\mathrm{min}} \mathrm{m}^{-1}$ as showed in Figure 2 . Electrical conductivity which is proportional to mixture pollutant concentrations and $\mathrm{pH}$ are plotted against number of exchanged pore volumes $\left(V / V_{0}\right)$ where $V$ is the injected volume and $V_{0}$ is the porous volume.

The $\mathrm{pH}$ value is basic along experiment (Figure $2 \mathrm{~b}$ ). The soil is more basic with depth. The eluate $\mathrm{pH}$ value increases by one unit whatever the used soil. This result is in agreement with some literature results (JeanSoro et al., 2012; Kumar et al., 2013). Wehrer and Totsch (2008) found a constant pH during leaching demolition waste and the municipal waste incineration ash. Authors assumed that the effluent $\mathrm{pH}$ of the demolition waste and the municipal waste incineration ash is due to apparent equilibrium dissolution of a readily available mineral phase. In these cases, the mineral phase is linked to the cement phase's composition. $\mathrm{pH}$ increases during leaching while the electric conductivity decreases (Figure 2). This result is also found in the works of Jean-Soro et al. (2012) which show that the most pH variation is corresponding to the large electric conductivity decrease and so pollutant concentration decrease. During the first $V / \mathrm{V}_{0}$, an easily mobilized fraction of elements is leached. It is a mixture of mineral and organic mobilized species. The sampling of the soil, which is the pre-treatment (drying, sieving) are well known to destroy the soil structure. Then, a loosely bound fraction of organic or mineral elements could be leached in soluble or colloidal form (Zhang et al., 2010; Lo et al., 2011).

Moreover, the initial electric conductivity decreases with soil depth (Figure 2a). It can be due to the anthropic heavy metal pollution witch always found in the first meters of the soil and decreases with the soil depth (Walden, 1964; Sposito, 1989). Indeed, the heavy metals from external inputs accumulate on the surface of the soil due to their very strong bond with the different solid phases. Thus, their concentrations decrease with depth. On the contrary, in the case of soils formed mainly from rocks particularly rich in metallic elements, the heavy metal content increases with depth. We can't conclude about the relationship between compounds migration and soil type. In fact, the dissolved compounds concentration is different in the case of soil 1 and soil 2 even though the same soil type.

Moreover, The basicity of soil promotes the formation of hydroxides which may also in a basic medium to associate with $\mathrm{OH}$ - ions and form anionic complexes such as $\mathrm{Pb}(\mathrm{OH})_{3}$ for lead, $\mathrm{Zn}(\mathrm{OH})_{3}{ }^{-}$and $\left.\mathrm{Zn}_{(\mathrm{O}} \mathrm{OH}_{4}\right)_{2}$ for $\mathrm{Zn}, \mathrm{Cd}\left(\mathrm{OH}_{3}\right)^{-}$for cadmium and $\mathrm{CrO}_{2}^{-}, \mathrm{CrO}_{4}{ }^{2-}$ for chromium. The increased $\mathrm{pH}$ contributes so to the reduction of the protons compete with respect to the metal ions and thus promotes their binding to the surface. 


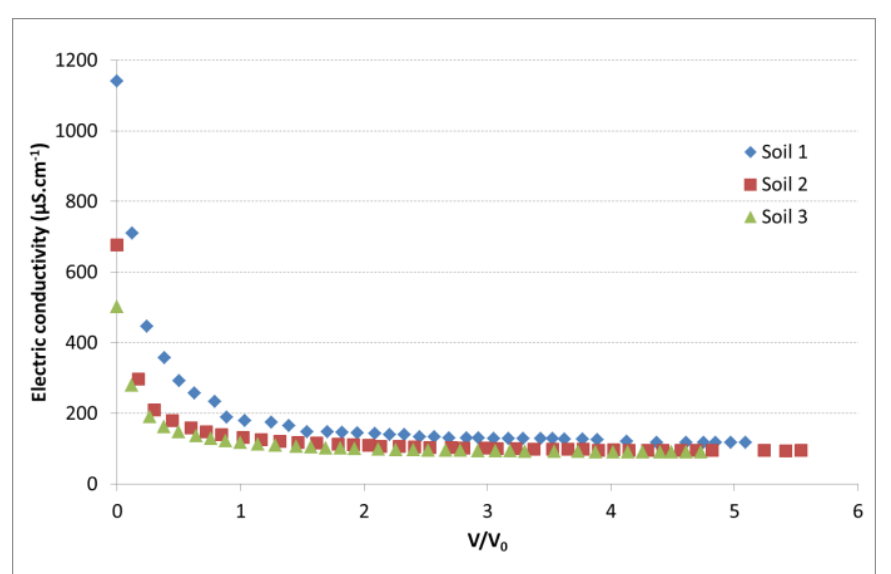

(a)

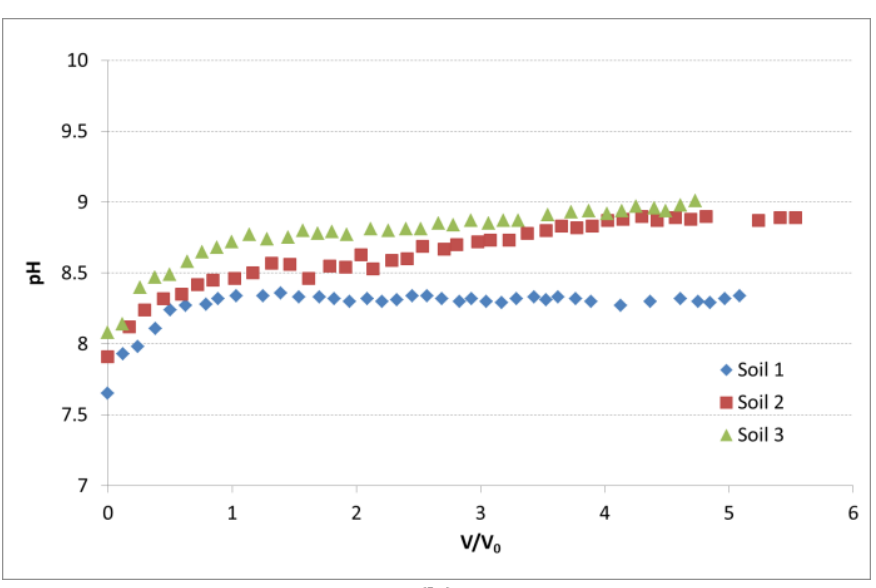

(b)

Figure 2. Electric conductivity (a) and pH (b) in the eluate solution for the three soils at $4.7 \mathrm{ml}^{\mathrm{min}} \mathrm{m}^{-1}$ flow leaching

In this study, it is considered that the maximum of the electric conductivity value to pollution concentration equal to $100 \%$. A depollution rate is defined as the extracted fraction. For the three tested soils, the depollution rate is about $85 \%$. The rate is more important in the case of the more polluted soil, which is of the order of $90 \%$ for equivalents injected pore volumes.

\section{Influence of the leaching flow rate}

In order to investigate the influence of flow rate on the leaching test efficiency, different flow rates are applied $\left(4.7 ; 10 ; 20 ; 40\right.$ and $\left.60 \mathrm{ml} \mathrm{min}^{-1}\right)$. In this experiment, the used soil is a sample of Soil 3. For different considered flow rates, the end of the experiment is set by obtaining a level corresponding to a constant concentration at the column outlet. This constant level corresponds to an average decrease in conductivity of $80 \%$ compared to baseline (Figure 3). The highest flow provides the most effective pollution control, since the bearing is obtained after several injected pore volumes $\left(10 V_{p}\right)$. For the same $V_{p}$, the higher rate allows to extract more pollutants.

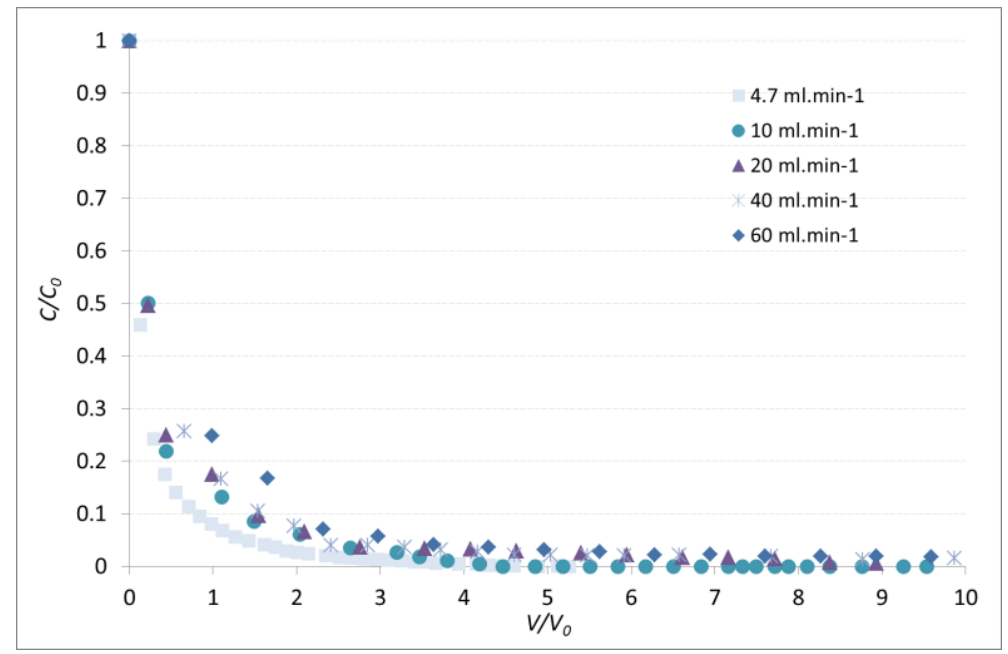

Figure 3. Experimental curve at different flow (soil 3)

The leached ions rate increases with velocity increase. This may be attributed to the effects of hydrodynamic chromatography resulted in a non-uniform distribution of pore velocities especially at high flow rate. Indeed, the minimum velocity is close to the grain surfaces according to Poiseuille's law.

This can increase the exchange kinetics between the immobile phase, pollutant set on the skeleton of the porous medium, and the mobile phase, the water flow. Thus, the rate of pollutants molecules desorption and dissolution were better. The efficiency of the leaching is thus not dependent on the water contact time with the polluted soil. These results are in agreement with, Wehrer and Totsche (2008) and Naka et al. (2016) study's conclusions. Wehrer and Totsche (2008) confirm that the electrical conductivity is independent on flow velocity and residence time in the case of MSWI ash. They suggest that it can be attributing to the near 
equilibrium conditions. For demolition debris, the leached solutions have a lower electrical conductivity in the case of lower velocity than the case of higher flow. They not explain this by non-equilibrium conditions, but they suggested a possible higher dissolution of inorganic colloids with high velocity. Naka et al. (2016) tested two flowrates on soil leaching and observed that the tested flow rates had little or no effect on the release of cations and anions.

\section{Down flow tests}

Figure 4 provides a description of leaching test results under unsaturated conditions at flow rates of 4.7 ml.min ${ }^{-1}$ and $113.6 \mathrm{ml} . \mathrm{min}^{-1}$. Results show different initial conductivities for leaching throughout the 3 soils for the two applied flow rates. Initials conductivities are smaller than those of the up flow tests. A constant conductivity is quickly achieved at the end of these experiments.

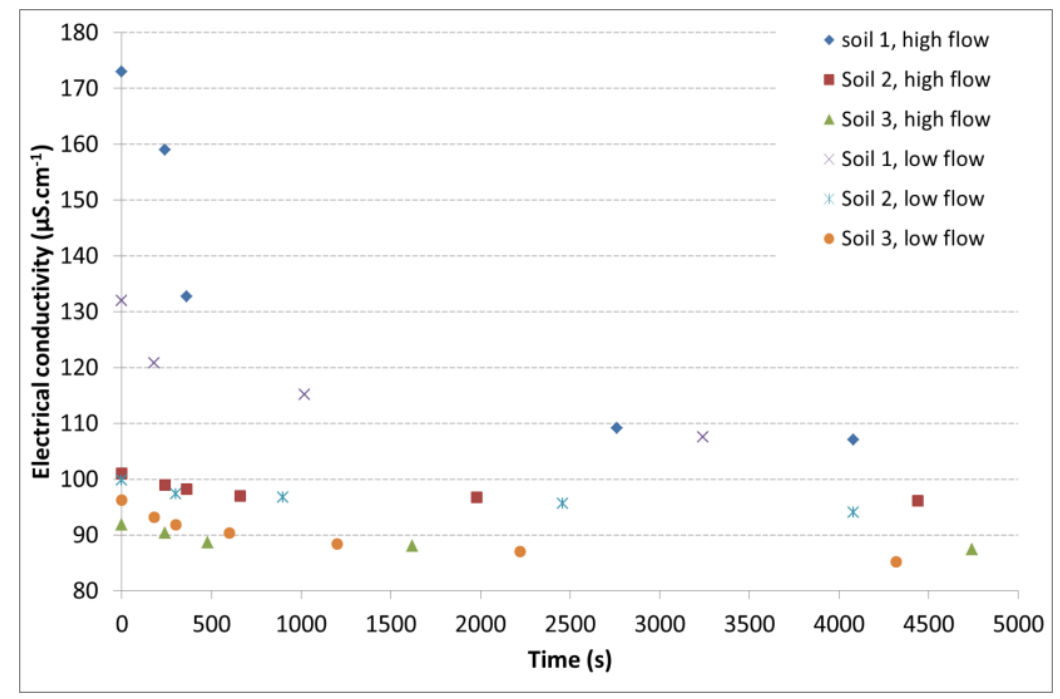

Figure 4. Evolution of electrical conductivity as function of the time for the three soil samples (4.7 ml.min-1, $113.6 \mathrm{ml}^{-\mathrm{min}^{-1}}$ )

In the case of soils 2 and 3, there is slight effect of the velocity on the evolution of the conductivity of the effluent. The electrical conductivity is near to water conductivity for all points showing a little extracted matter. Both used flow rates provide dissolved equivalent yields of extracted pollutant for different soil samples. Indeed, only $1 \mathrm{~L}$ of injected water which is equivalent to $6.08 \mathrm{VP}, 6 \mathrm{VP}$ and $6.21 \mathrm{VP}$ respectively for Soil 1, Soil 2 and Soil 3.

The comparison between the leaching under up flow and down flow conditions shows that the first case allows greater depollution rate. Soils under those conditions present greater conductivity values than in the case of down flow conditions. This is due to the fact that the contact surface between water and the soil grains is larger than in the second case. The water flow can be considered homogeneous in the case of up flow but in the case of down flow, and with the addition of the gravity effect a "channeling" or "by pass" system takes place in the porous media. The injected pore volumes are equivalent in both cases, but the recovered volumes are less important in the case of down flow trials which are due to the amount of residual water in the soil. The leaching effectiveness is higher in up flow conditions. This trend can be observed after an intense rain event. The soil is at first non-saturated and then a saturated condition is followed that increase dissolved material transport.

\section{Conclusion}

Leaching experiments under conditions of up flow and down flow unsaturated soils have been carried in this work. Soils used are mainly real soils polluted with heavy metals. The results of the leaching are analyzed by monitoring electrical conductivity and $\mathrm{pH}$. The change in leaching flow rate is investigated in this work. It shows that a low flow rate is as effective as a high values for the dissolved material extraction. Such choice has the advantage of using smaller amount of water, but there is a disadvantage of high required time for this operation. The extracted pollution decreases according to the depth of the samples, which may be due to the dominant nature of anthropogenic pollution by heavy metals from the soil. The soil type influences the amount of dissolved material, and thus the migration of pollution between the various layers. During a rain event: each layer is different filter pollution and will transmit it to the next layer. Down flow unsaturated experiments have shown lower mobilization of the dissolved pollutants compared to up flow conditions. 


\section{References}

AAEE, 1993. American Academy of Environmental Engineers. Soil Washing/Soil Flushing, Innovative Site Remediation. Anderson, W.C. (Ed), vol3, WASTEC.

Beesley, L., Moreno-Jimenez, E., Celemente, R., Lepp, N., Dickinson, N., 2010. Mobility of arsenic, cadmium and zinc in a multi-element contaminated soil profile assessed by in-situ soil pore water sampling, column leaching and sequential extraction. Environmental Pollution 158 (1) : 155-160.

BRGM, 1978. Carte géologique ${ }^{\circ} 698$ de Lyon, BRGM editions

BRGM, avril 2008. Bases de données relatives à la qualité des sols : contenu et utilisation dans le cadre de la gestion des sols pollués, V.0.1

Chappell, M., Middleton, M., Price, C., 2013. Chemical and physical changes in tropical soils from seawater exposure and subsequent rainwater washes. Procedia Earth and Planetary Science 7: 131-134.

Colombani, N., Mastrocicco, M., Di Giuseppe, D., Faccini, B., Coltorti, M., 2015. Batch and column experiments on nutrient leaching in soils amended with Italian natural zeolitites. Catena 127: 64-71.

Dermont, G., Bergeron, M., Mercier, G., Richer-Laflèche, M., 2008. Soil washing for metal removal : A review of physical/chemical technologies and field applications. Journal of Hazardous Materials 152(1): 1-31.

Fedje, K.K., Yillin, L., Strömvall, A.M., 2013. Remediation of metal polluted hotspot areas through enhanced soil washingEvaluation of leaching methods. Journal of Environmental Management 128: 389-496.

Jean-Soro, L., Bordas, F., Bollinger, J.C., 2012. Column leaching of chromium and nickel from a contaminated soil using EDTA and citric acid. Environmental Pollution 164: 175-181.

Kalbe, U., Berger, W., Eckardt, J., Simon, F.G., 2008. Evaluation of leaching and extraction procedures for soil and waste. Waste Management 28(6): 1027-1038.

Kumar, M., Furumai, H., Kurisu, F., Kasuga, I., 2013. Potential mobility of heavy metals through coupled application of sequential extraction and isotopic exchange: Comparison of leaching tests applied to soil and soakaway sediment. Chemosphere 90(2): 796-804.

Lafuente, A.L., González, C., Quintana, J.R., Vázquez, A., Romero, A., 2008. Mobility of heavy metals in poorly developed carbonate soils in the Mediterranean region. Geoderma 145(3-4): 238-244.

Li, Q.S., Liu, Y.N., Du, Y.F., Cui, Z.H., Shi, L., Wang, L., Li, H.J., 2011. The behavior of heavy metals in tidal flat sediments during fresh water leaching. Chemosphere 82(6): 834-838.

Lo, I.M.C., Tsang, D.C.W., Yip, T.C.M., Wang, F., Zhang, W., 2011. Influence of injection conditions on EDDS-flushing of metal-contaminated soil. Journal of Hazardous Materials 192(2): 667-675.

Matos, A.T., Fontes, M.P.F., da Costa, L.M., Martinez, M.A., 2011. Mobiblity of heavy metals as related to soil chemical and mineralogical charactristics of Brazilian soils. Environmental Pollution 111(3): 429-435.

Mulligan, C.N., Yong, R.N., Gibbs, B.F., 2001. Remediation technologies for metal-contaminated soils and groundwater: an evaluation. Engineering Geology 60(1-4): 193-207.

Naka, A., Yasutakab, T., Sakanakuraa, H., Kalbec, U., Watanabed, Y., Inobad, S., Takeoe, M., Inuie, T., Katsumie, T., Fujikawaf, T., Satof, K., Higashinog, K., Someyag, M., 2010. Column percolation test for contaminated soils: Key factors for standardization. Journal of Hzardous Materials 320: 326-340.

Pang, L., Close, M., Schneider, D., Stanyon, G., 2002. Effect of pore-water velocity on chemical nonequilibrium transport of $\mathrm{Cd}, \mathrm{Zn}$, and $\mathrm{Pb}$ in alluvial gravel columns. Journal of Contaminant Hydrology 57(3-4): 241-258.

Plassard, F., Winiarski, T., Petit-Ramel, M., 2000. Retention and distribution of three heavy metals in a carbonated soil: comparison between batch and unsaturated column studies. Journal of Contaminant Hydrology 42(2-4): 99-111.

Sposito, G., 1989. The chemistry of soils. Clarendon Press, Oxford, 277p.

Viglianti, C., De Brauer, C., Laforest, V., Bourgois, J., 2008. Meilleures techniques disponibles de lavage de sols contaminés par les HAP : Etude d'un procédé basé sur les cyclodextrines. Congrès International Gestion Déchets Solides et Développement Durable (GDS/DD), Hammamet, Tunisia. 6p,

Walden, R., 1964. Complément de chimie générale chimie descriptive, Tome II.

Wehrer, M., Totsche, K.U., 2008. Effective rates of heavy metal release from alkaline wastes - Quantified by column outflow experiments and inverse simulations. Journal of Contaminant Hydrology 101(1-4): 53-66.

Wennrich, R., Daus, B., Müller, K., Stärk, H.J., Brüggemann, L., Morgenstern, P., 2012. Behaviour of metalkoids and metals from highly polluted soil samples when mobilized by water -Evaluation of static versus dynamic leaching. Environmental Pollution 165: 59-66.

Yang, Z., Zhang, S., Liao, Y., Li, Q., Wu, B., Wu, R., 2012. Remediation of heavy metal contamination in calcareous soil by washing with reagents: A column washing. Procedia Environmental Sciences 16: 778-785.

Zhang, W., Huang, H., Tan, F., Wang, H., Qiu, R., 2010. Influence of EDTA washing on the species and mobility of heavy metals residual in soils. Journal of Hazardous Materials 173(1-3): 369-376. 